Research Article

\title{
Shaking Table Experiment and Energy Analysis of a New Rebar Isolation Pier
}

\author{
Yifu Xiao $\mathbb{D}$, Shouping Shang $\mathbb{D}$, and Zhen Wang $\mathbb{B}$ \\ College of Civil Engineering, Hunan University, Changsha, Hunan 410082, China \\ Correspondence should be addressed to Zhen Wang; wangzhen88@hnu.edu.cn
}

Received 11 September 2020; Revised 10 December 2020; Accepted 3 January 2021; Published 30 January 2021

Academic Editor: Xuemei Liu

Copyright (c) 2021 Yifu Xiao et al. This is an open access article distributed under the Creative Commons Attribution License, which permits unrestricted use, distribution, and reproduction in any medium, provided the original work is properly cited.

\begin{abstract}
This paper introduces the structure and principle of a new isolation device-rebar isolation pier-which is mainly composed of vertical steel bar and asphalt ointment. It is used to reduce the earthquake action of the building structure. Compared with other isolation devices, the rebar isolation pier has the following advantages: simple structure, convenient construction, low cost, simple maintenance, and easy to fetch material. In the experiment, the test model is a two-layer frame, and the Taft wave and the Wolong wave were selected to simulate the actual earthquake. In order to study the damping effect of asphalt ointment, two different isolation piers (filled and unfilled with asphalt ointment) were included. The dynamic characteristics and isolation effect of the rebar isolation pier are studied by analysis of acceleration, displacement, and hysteresis loops. At the same time, according to the principle of energy method, the energy balance equation of the rebar isolation pier was proposed, and the total input energy and damping energy are used to analyze the energy of the isolation pier. The results demonstrate that the rebar isolation pier can effectively reduce the natural frequency, acceleration response, and absorbed seismic energy of the structure when the peak ground acceleration reaches $0.3 \mathrm{~g}$, and it still has the potential to withstand greater seismic action.
\end{abstract}

\section{Introduction}

For a long time, earthquakes brought human beings a painful and profound disaster. The most serious disasters in earthquakes are the loss of life and property caused by house collapse. For example, according to official reports, the Wenchuan earthquake in Sichuan province, China, killed about 70,000 people in 2008 , most of them caused by the houses' collapse [1].

At present, there are two main solutions to the aseismic problem. One way is to enhance the strength and stiffness of the structure by increasing reinforcing bars or dimensions of concrete members. However, this method will increase the weight of the structure and make the structure bear more seismic force, which will lead the strength and stiffness of the structure to be increased again, finally forming a vicious circle. The other way is to use isolation techniques to separate structures or components from the seismic ground motion by increasing the flexibility of the system and providing appropriate damping. Because of its remarkable advantages in shock absorption control effect, disaster prevention, and reduction as well as social and economic benefits, isolation technology has become the most effective technology among all energy dissipation technologies [2]. According to the research of isolation technology, it can be divided into the following types:

Laminated rubber bearing: the commonly used laminated rubber bearing is composed of two parts: one is a laminated thin steel plate and the other is a multilayer rubber sheet. The two parts are alternately stacked on each other and bonded by a special process to make an isolation bearing. Under the vertical load, the rubber layer bound by the steel plate bears the vertical load together, so that the rubber bearing has enough vertical bearing capacity and stiffness. When the isolation bearing is subjected to the horizontal earthquake, the rubber layer can provide considerable lateral displacement without loss of stability but also can effectively consume seismic energy $[3,4]$.

Friction pendulum bearing: this isolation layer is a friction layer with low shear strength between the underground foundation and the superstructure. It is generally 
made of materials with low friction coefficient, such as graphite and sand, so that the building can slide horizontally in the event of an earthquake. Due to friction and slip, the transfer of seismic action to the upper part of the structure is weakened. Meanwhile, friction also dissipates the energy of the earthquake during the sliding process of the building. However, because its isolation layer does not have the horizontal recovery force, the slip generated during the earthquake is often unable to recover $[3,5,6]$.

Although the existing isolation technology has a good isolation effect, their disadvantages are obvious. Moreover, the relatively high price and complex manufacturing process of isolation technology limit its spread in remote and underdeveloped rural areas. According to the 2008 Wenchuan earthquake investigation report, most of the earthquake damage occurred in remote and economically backward rural areas rather than cities.

At present, seismic force, displacement, and other indexes are widely used in seismic research and design in the world. However, seismic motion is a continuous process and this method only reflects the maximum seismic force exerted on the structure but ignores the impact of the process. Although this method has the advantages of simple and easy to use, many seismic damage analysis results show that this method both in terms of the intensity of the ground motion input and in terms of seismic bearing capacity of structures or components is not enough to determine the effect of seismic characteristics on the structure and the true response of the structure in the process of seismic action [7].

The effect of earthquake on structure also can be regarded as a process of energy transfer, transformation, and consumption, and the basic principle of reducing or controlling earthquake response is mainly to dissipate the input energy of earthquake in an appropriate way. In an earthquake, the energy obtained by a building is related to its natural vibration period and total mass, and when the mass and natural vibration period are determined, the energy input by the earthquake is a relatively stable value, and other factors have little influence. Therefore, compared with the traditional analysis method, the energy method not only includes the most important design factors but also can better reflect the whole process of the structure and the elastoplastic performance under the earthquake $[8,9]$. Although the energy method cannot directly calculate the seismic force and the process is more complex, as a new seismic effect analysis method, it can make up for the deficiency of the traditional analysis method.

\section{The Rebar Isolation Pier}

A large number of seismic studies show that the areas far away from the epicenter are mainly affected by horizontal vibration, and the houses in rural areas are relatively dispersed $[10,11]$, so the main purpose of the rebar isolation pier is to isolate the horizontal earthquake. Compared with the urban buildings, the height of rural houses is lower and the dead weight is lighter [12].
In view of these characteristics, a low-cost isolation device-rebar isolation pier-was proposed. The rebar isolation pier is mainly composed of ordinary circular section steel bar and asphalt ointment; therefore, the cost is relatively reduced. By prolonging the natural period, the seismic acceleration of the upper structure can be significantly reduced. This system is simple in construction, low in cost, and convenient in construction. It is mainly applied to masonry and concrete structure with a height-width ratio less than 2.

2.1. Structure and Arrangement. The structure and arrangement of the rebar isolation pier are shown in Figure 1.

The following sections introduce in detail the main components and construction steps of the reinforced isolation pier.

2.1.1. Vertical Steel Bar. The vertical steel bar is an ordinary hot rolled steel bar with a circular section, so the isolation effect in any direction is the same. It has two main functions: one is to bear gravity load and seismic load; the other is to provide appropriate stiffness of the seismic isolation layer to meet the requirements of seismic isolation.

2.1.2. Asphalt Ointment. The asphalt ointment in the rebar isolation pier can be divided into two types according to their positions: one is the asphalt ointment between the mat pier and the top cover plate, which is used to isolate them to prevent the horizontal stiffness of the vertical steel bar from being affected by the contact between the mat pier and the top cover plate; the other is the asphalt ointment around the pier and the steel bar, which can increase the damping of the rebar isolation pier, dissipate seismic energy during an earthquake, and wrap the vertical steel bars to prevent the steel bar from rusting.

The asphalt ointment is made of asphalt and powder (lime-fly ash). By adjusting the ratio of powder to asphalt, the hardness and temperature characteristics of the asphalt ointment can be changed. There are two main requirements for asphalt ointment. The first is not hardening in winter; otherwise, the horizontal stiffness and damping of the isolation layer will increase. The second does not flow in summer, which can ensure the protection of the steel bars.

2.1.3. Mat Pier. The mat pier made of steel is arranged between upper and lower cover plate. There is a gap of about $10 \mathrm{~mm}$ between the top of the mat pier and the upper cover plate, which is filled with asphalt ointment. Because the elastic modulus of asphalt ointment is much smaller than steel bar, the mat pier does not bear the load of the upper structure under the earthquake with low seismic intensity. Only when encountering rare earthquake action which makes the steel bars produce greater tilting and the upper cover plate contact with the mat pier, the mat pier will bear the load of the upper part. So as long as the mat pier has enough bearing capacity, the house will not collapse by the steel bar yielding. 

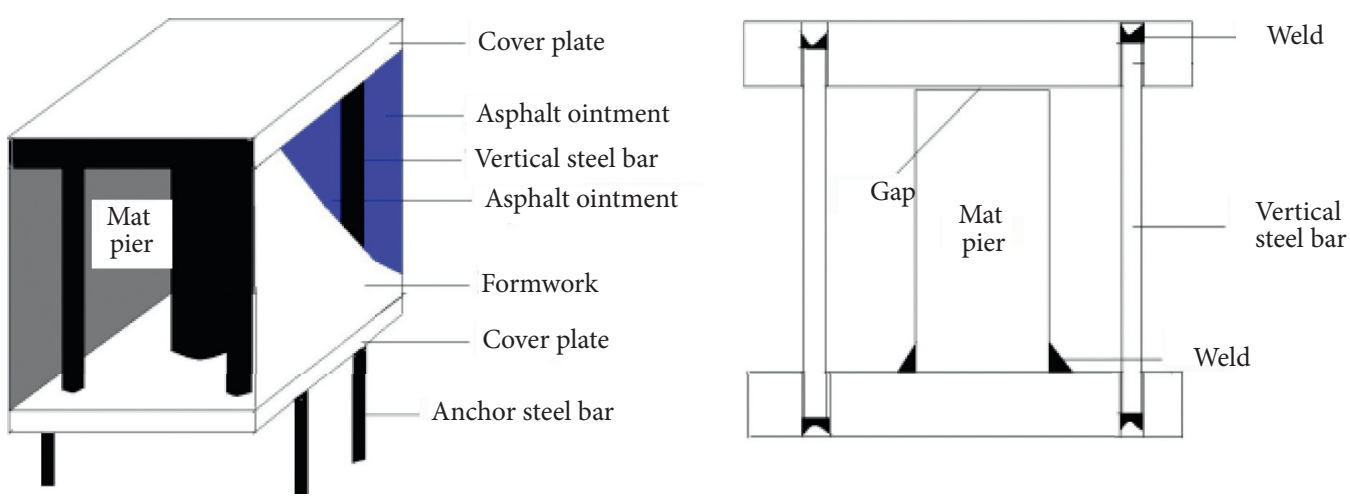

(a)

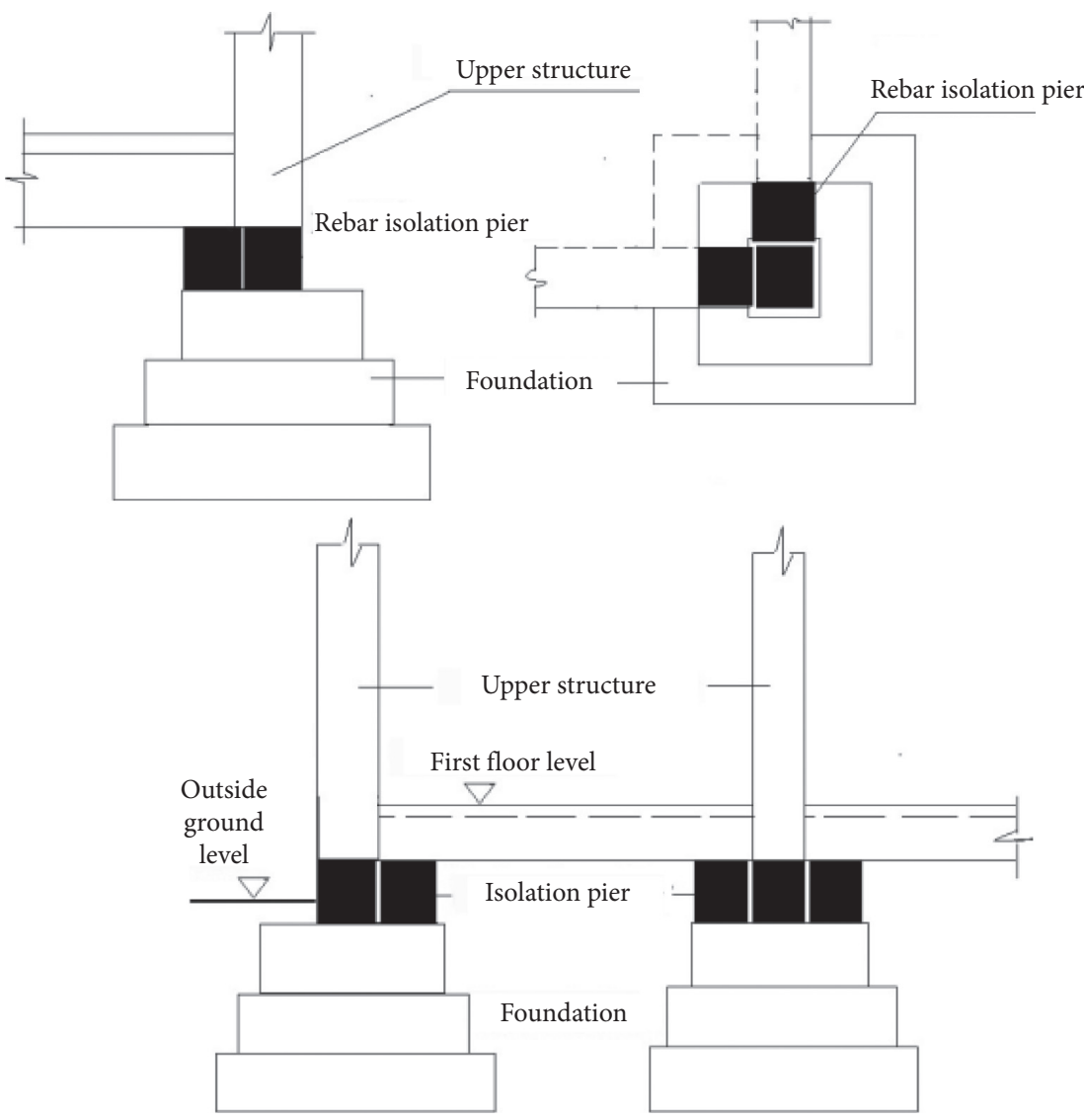

(b)

FIGURE 1: The structure and arrangement of the rebar isolation pier: (a) structural details of the rebar isolation pier and (b) floor plan and elevation plan of the rebar isolation pier.

2.1.4. Cover Plate. The cover plate is arranged at both ends of the vertical steel bar and generally made of steel; its main function is to fix the vertical steel bar and transfer the force from the upper structure to the rebar isolation pier and foundation. There are some steel bars welded on the outside of the cover plate for anchoring the rebar isolation pier in concrete; if there are embedded steel plates in concrete, the upper plate can also be welded directly to the embedded plate.
2.1.5. Construction Steps. The construction steps are as follows: first, pour the foundation concrete in layers; secondly, placing the rebar isolation pier before pouring the topmost concrete of foundation and ensure that the anchor steel bars of the isolation pier are inserted into the foundation; and finally, pour a layer of horizontal frame on the rebar isolation pier and then building upper structure on it.

It is worth noting that all the above statements are based on single foundation under the column, but by changing the 
connection method with structure, the rebar isolation pier can also be applied to other foundation forms.

2.2. Isolation Principle. The isolation principle of the rebar isolation pier is shown in Figure 2.

According to the "Code for Seismic Design of Buildings" of China, the horizontal seismic force is as follows:

$$
F=\alpha G,
$$

where $\alpha$ is seismic influence coefficient and $G$ is gravity load.

It can be seen from Figure 2(a) that when the natural vibration period of structure $(T)$ is larger than the characteristic period of the site $\left(T_{G}\right), \alpha$ decreases with the increase of $T$ [13]. For building structures, $T$ increases with the decrease of structural lateral stiffness $(K)$. Therefore, when the stiffness of the rebar isolation pier decided by the stiffness of vertical steel bar decreases, $\alpha$ will decrease. According to equation (1), the seismic force $\mathrm{F}$ will also decrease.

As can be seen from Figure 2(b), its calculation model can be simplified as an eccentric compression rod with one end fixed and the other end is fixed by sliding; due to its symmetry, it can be further simplified to a simple vibration system. So, the vertical steel bar is the most important component of the rebar isolation pier. Generally speaking, the smaller the horizontal stiffness of the vertical steel bar, the better the isolation effect but the lower the bearing capacity.

From the perspective of the energy method, the stiffness of the rebar isolation pier is low, which increases the natural vibration period of the structure and also reduces the seismic force as well as the total energy input of ground vibration [9]. In addition, under the action of strong earthquakes, the isolation pier enters inelastic state before the superstructure and absorbs a large amount of seismic energy, which makes the superstructure move horizontally like a rigid body and maintain elasticity or not enter obvious plastic state. It can be approximately considered that all seismic energy is concentrated in the rebar isolation pier and dissipated or absorbed by it.

\section{Shaking Table Test of the Rebar Isolation Pier}

The shaking table text of earthquake simulation is performed in the National Level Experiment Education Model Center of Civil Engineering of Shandong Jianzhu University.

3.1. Model Design. The experimental model is divided into two parts: upper frame and lower isolation layer. The upper frame structure only moves horizontally under the action of earthquake, and the horizontal stiffness between floors is much higher than the isolated layer. Therefore, the experimental model can be simplified as a single quality system. Its total gravity load value $G$ is $82.4 \mathrm{kN}$ and size and structure are shown in Figure 3.

The rebar isolation pier is composed of two steel plates and vertical steel bars between the steel plates. In order to meet the requirements of bearing capacity, stiffness, and seismic isolation, the HRB400 steel bar with a diameter of $10 \mathrm{~mm}$ and a free height of $300 \mathrm{~mm}$ is used as the vertical steel bars in this experiment [14]. The measured average yield strength, tensile strength, and elongation (within 5 times steel bar diameter) of the steel bars are $502 \mathrm{MPa}$, $650 \mathrm{MPa}$, and $26 \%$, respectively. The isolation layer consists of 4 rebar isolation piers and each rebar isolation pier contains 8 vertical steel bars (a total of 32).

The asphalt ointment is made from a mixture of asphalt and lime-fly ash at a high temperature with a mass ratio of $10: 1$. Among them, the rebound ratio rate of asphalt is $85 \%$, the bonding strength is $2.5 \mathrm{~kg} / \mathrm{cm}^{2}$, and the lime-fly ash is a common type used in building, the main component of which is calcium carbonate. All the experiments were carried out at $29^{\circ} \mathrm{C}$.

During production, stack the upper and lower steel plates together and punch holes in where the steel bars will be placed, then insert the vertical steel bars into the holes, fixed by welding at both ends of the steel bar, and finally install formwork around the rebar isolation pier and pour asphalt ointment. The size and structure are shown in Figure 4, and the real object is shown in Figure 5.

In order to facilitate construction and installation, the anchor steel bar is canceled, the upper cover plate of the isolation pier is directly welded to the embedded part of the frame structure, the lower cover plate is directly connected to the vibration table by bolts, and the mat pier is positioned outside the isolation pier. The model design is different from the actual project described previously, but these differences did not change the isolation principle and had little effect on the experimental results.

3.2. Experimental Facilities and Loading Plan. The main equipment of the shaking table is provided by SERVOTEST company in the UK, the table size of which is $3 \mathrm{~m} \times 3 \mathrm{~m}$, the maximum load is $10 t$, and the maximum horizontal acceleration is $1.5 \mathrm{~g}$.

The measuring device is the 891-2 acceleration sensor developed by the Institute of Engineering Mechanics of China Earthquake Administration. They are arranged in the center of the first floor and the sharking table to record the output data and input data, respectively (see Figure 3).

The data acquisition device is a DASP signal analysis system developed by China Orient Institute of Noise \& Vibration (see Figure 6).

In this experiment, the WL wave recorded by the Wolong seismic station during the Wenchuan earthquake and the Taft wave were selected. The maximum acceleration of the input was gradually increased from $0.1 \mathrm{~g}$ to $0.3 \mathrm{~g}$. In order to analyze the effect of asphalt ointment on base isolation, comparative tests were carried out. Detailed test information is shown in Table 1. In addition, the frequency sweep of white noise was carried out to test the natural vibration characteristics of the structure.

3.3. Experimental Phenomena and Results. In the nonasphalt test, even if the acceleration peak value is small, the response of the superstructure is relatively large. After the shaking 


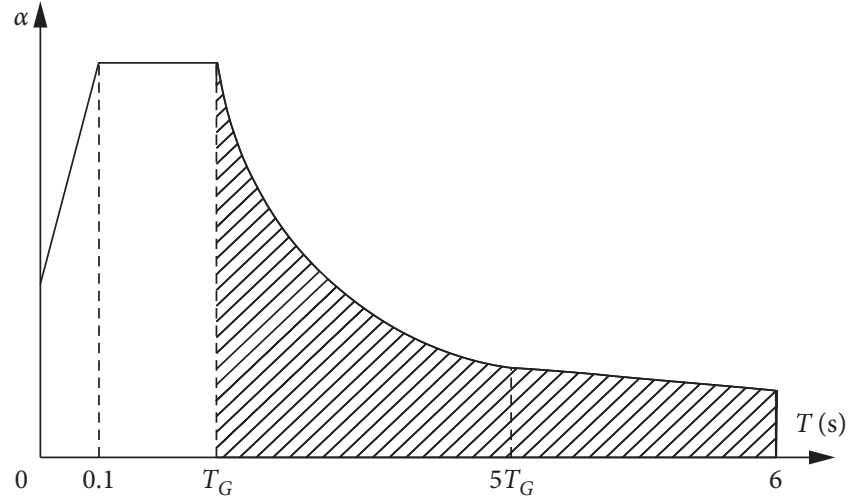

(a)

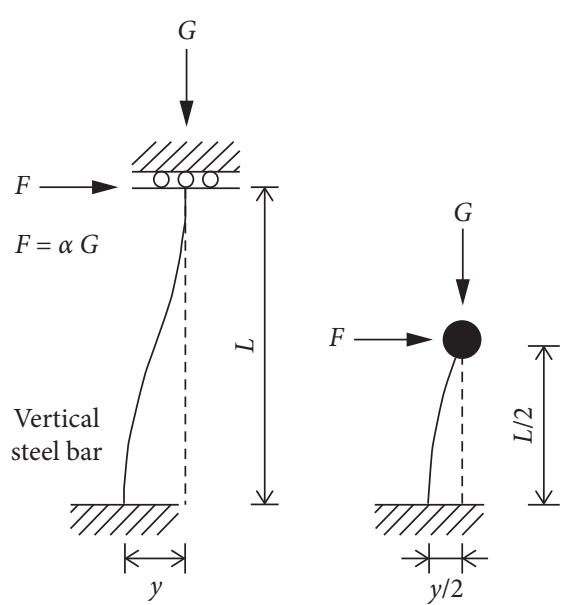

(b)

Figure 2: The isolation principle of the rebar isolation pier: (a) seismic influence coefficient curve and (b) simplified calculation model of vertical steel bar.

table stops, the upper structure still vibrates freely. The phenomena show that the rebar cannot offer adequate damping. However, when the asphalt is added, the responses of the superstructure attenuate quickly, which means that the asphalt can add adequate damping.

With the increase of input acceleration, the superstructure wobbles more obviously, but even if the input acceleration reaches $0.3 \mathrm{~g}$, the isolation layer can still reset to the initial position after the test is completed and there was no visible damage in the vertical steel bars after all tests were completed.

The acceleration and displacement time history are shown in Figure 7.

\section{Analyses and Discussions of Experiment Results}

4.1. Natural Vibration Characteristic. In the test process, the frequency sweep of white noise with low amplitude was carried out, and according to the results, the natural vibration period and damping ratio of the isolated system are obtained by the transfer function method [15]. The results are shown in Table 2. As can be seen from the table, one has the following:

(1) When asphalt ointment is not added and the input seismic acceleration does not exceed $0.1 \mathrm{~g}$, the natural vibration period and damping ratio of the structure before and after vibration change slightly. It indicates that, under the action of small ground motion, there is no damage to the isolation layer.

(2) The natural vibration period decreases slightly after the asphalt ointment is added. This is because the asphalt ointment is providing certain lateral support to the steel bars and increasing the stiffness of the isolation pier.

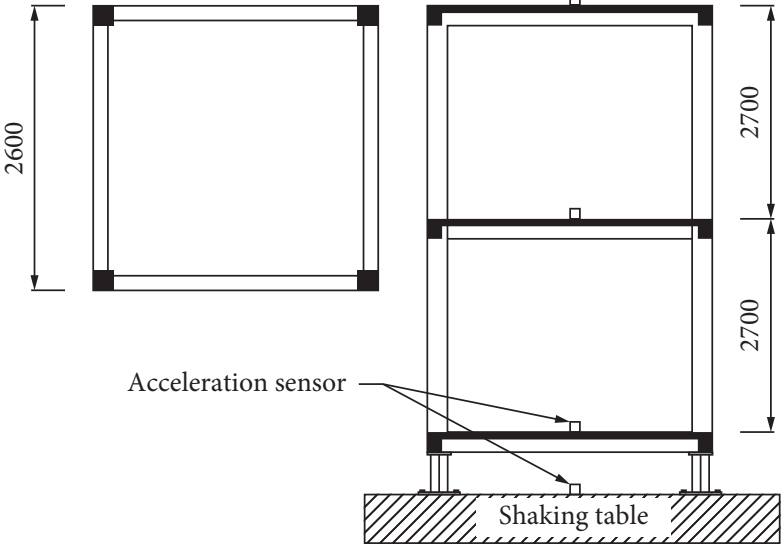

Figure 3: Plan view of upper frame (mm).

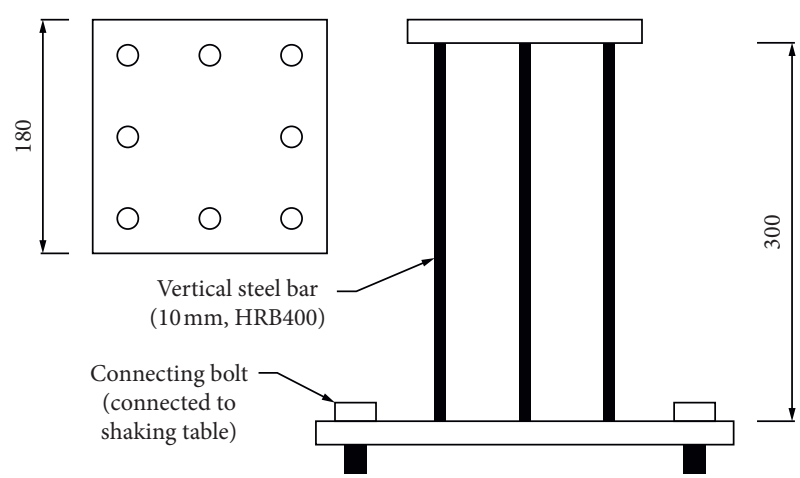

Figure 4: Size and structure of rebar isolation pier in this text (mm).

(3) After adding asphalt, the change rate of the natural vibration period before and after the test is larger than that without asphalt ointment. This may be due 


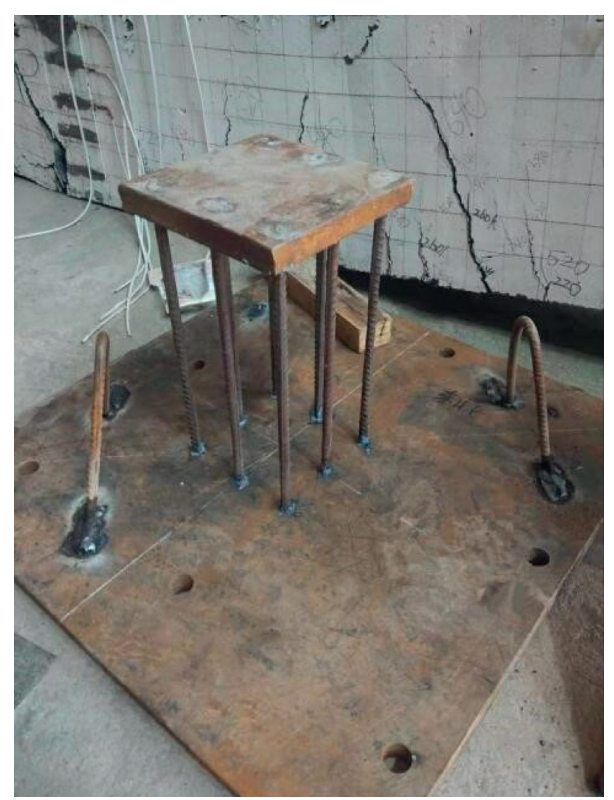

(a)

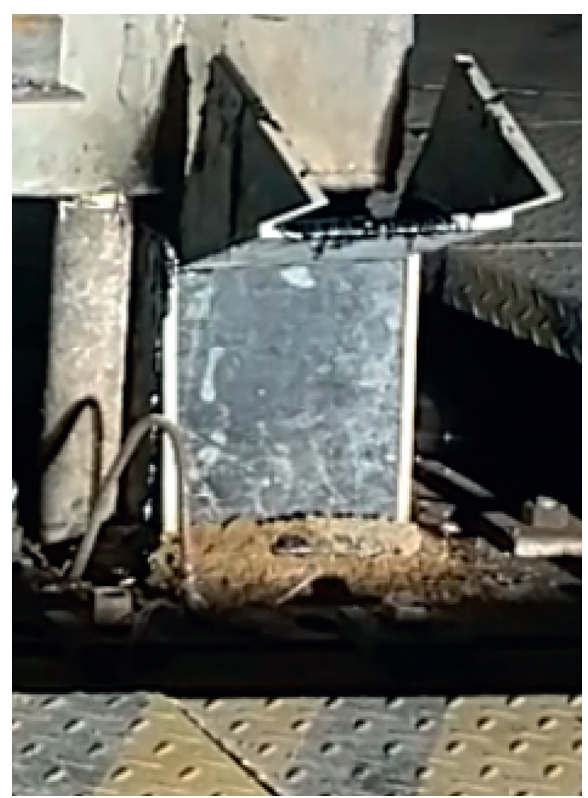

(b)

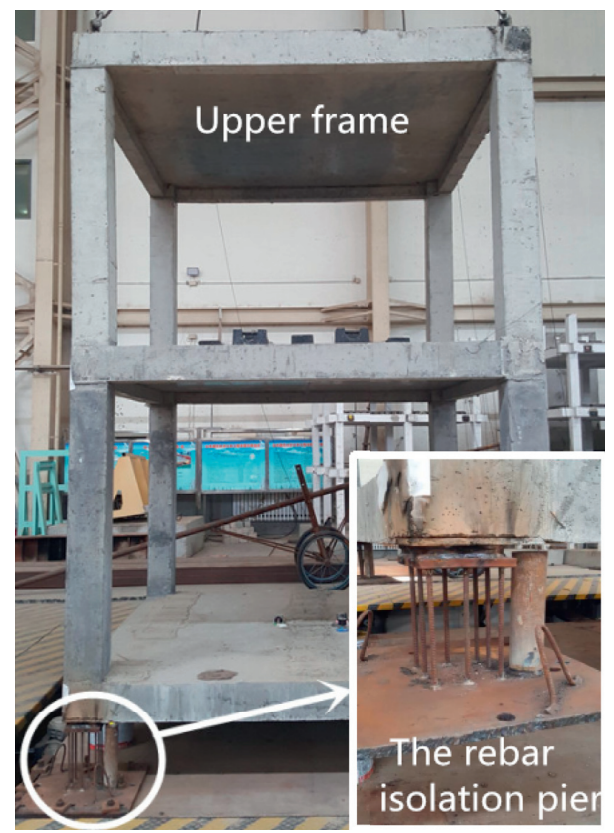

(c)

FIGURE 5: Real object of the rebar isolation pier: (a) rebar isolation pier without asphalt ointment, (b) rebar isolation pier with asphalt ointment, and (c) installed experimental model.

to the plastic deformation of the vertical steel bar when the input peak seismic acceleration reaches $0.3 \mathrm{~g}$. However, this is still a small change; we think that the plastic deformation is limited and only occurs at the edge of the section of the steel bar.

(4) After adding asphalt, the damping ratio is more than doubled, which indicates that asphalt ointment can obviously improve the damping of the rebar isolation pier.

4.2. Acceleration and Horizontal Displacement. Acceleration reduction is one of the most important indexes to evaluate the isolation effect. The experiments reproduced the acceleration and displacement of the model at the PGA 


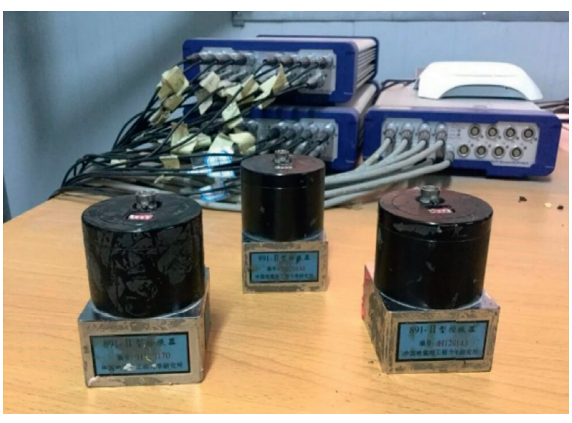

(a)

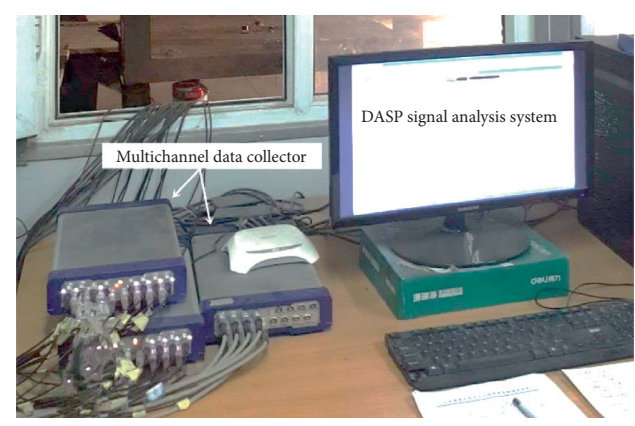

(b)

FiguRE 6: (a) 891-2 acceleration sensor and (b) data acquisition and analysis system.

TABLE 1: Test information.

\begin{tabular}{lcccc}
\hline Test no. & Input wave & Peak acceleration of design $(\mathrm{g})$ & Peak acceleration of actual & Notes \\
\hline WN1 & White noise & 0.10 & - & Without asphalt \\
WL0 & Wolong & 0.10 & $0.100 \mathrm{~g}$ & Without asphalt \\
Taft0 & Taft & 0.10 & $0.099 \mathrm{~g}$ & Without asphalt \\
WN2 & White noise & 0.10 & - & Without asphalt \\
WN3 & White noise & 0.10 & $0.111 \mathrm{~g}$ & With asphalt \\
WL1 & Wolong & 0.10 & $0.193 \mathrm{~g}$ & With asphalt \\
WL2 & Wolong & 0.20 & $0.270 \mathrm{~g}$ & With asphalt \\
WL3 & Wolong & 0.30 & $0.103 \mathrm{~g}$ & With asphalt \\
Taft1 & Taft & 0.10 & $0.191 \mathrm{~g}$ & With asphalt \\
Taft2 & Taft & 0.20 & - & With asphalt \\
WN4 & White noise & 0.10 & With asphalt \\
\hline
\end{tabular}

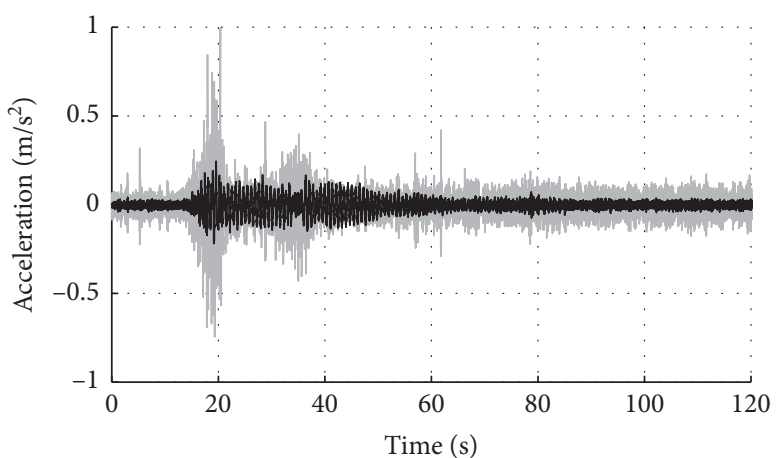

Input acceleration time history

Output acceleration time history

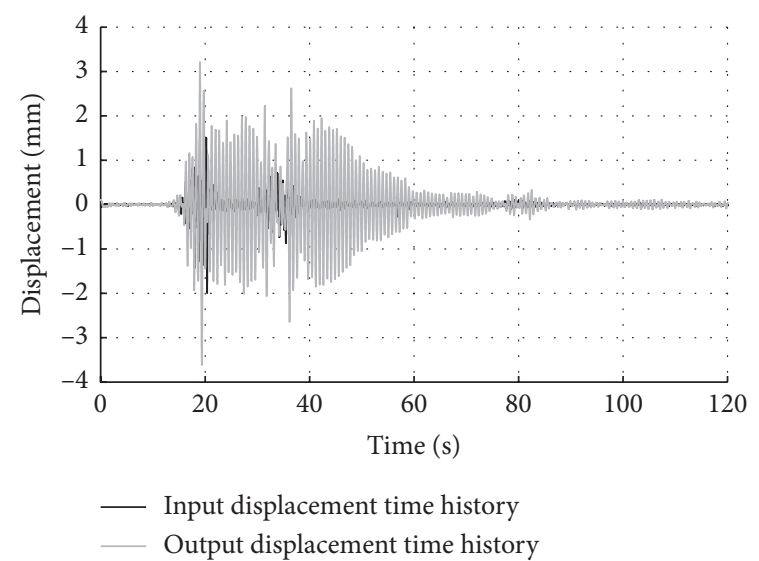

(a)

Figure 7: Continued. 


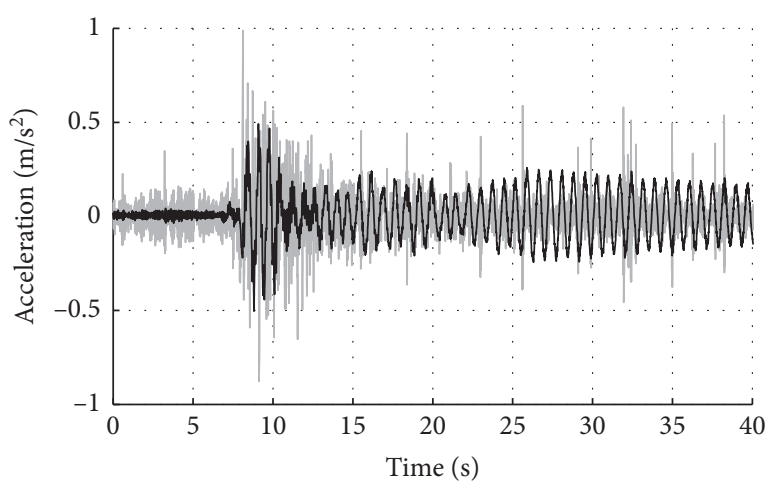

- Input acceleration time history

— Output acceleration time history

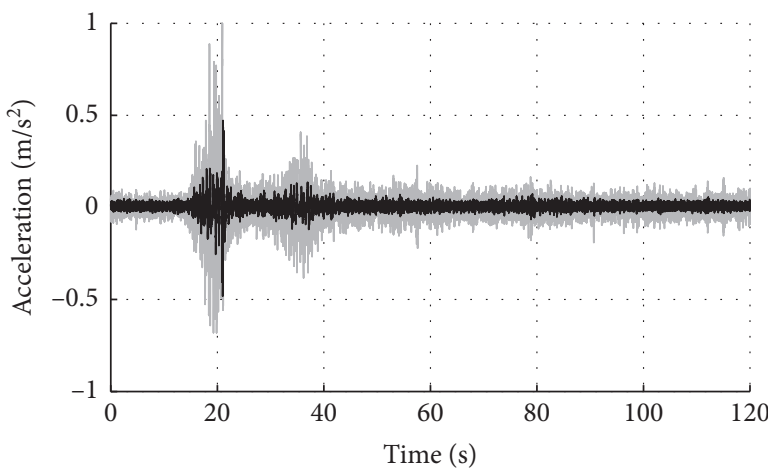

- Input acceleration time history

— Output acceleration time history

(c)

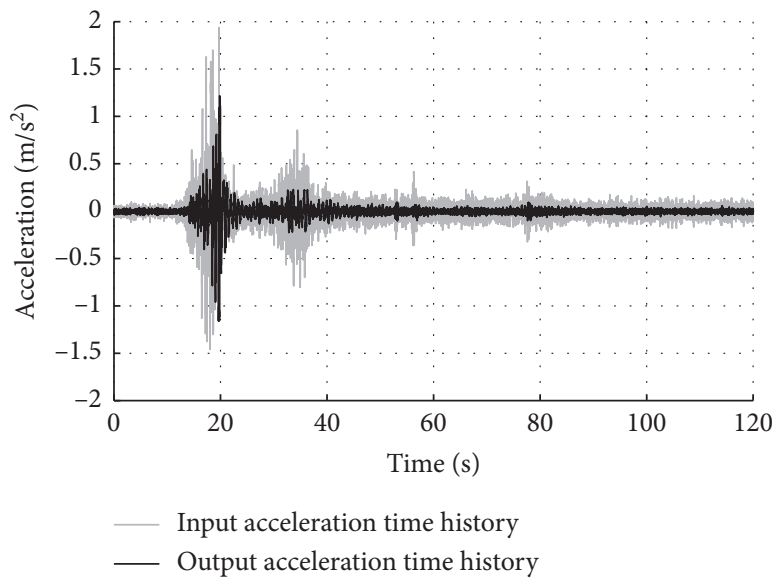

(b)
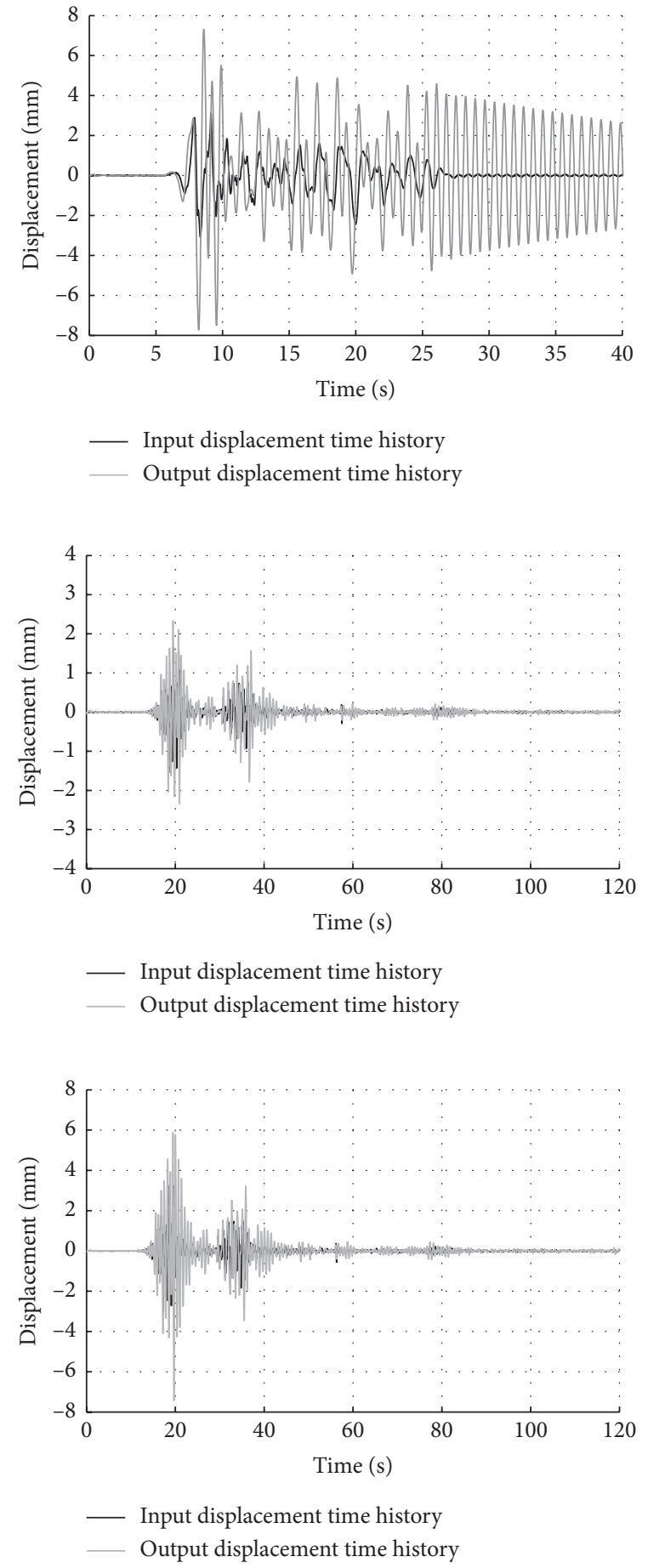

(d)

Figure 7: Continued. 


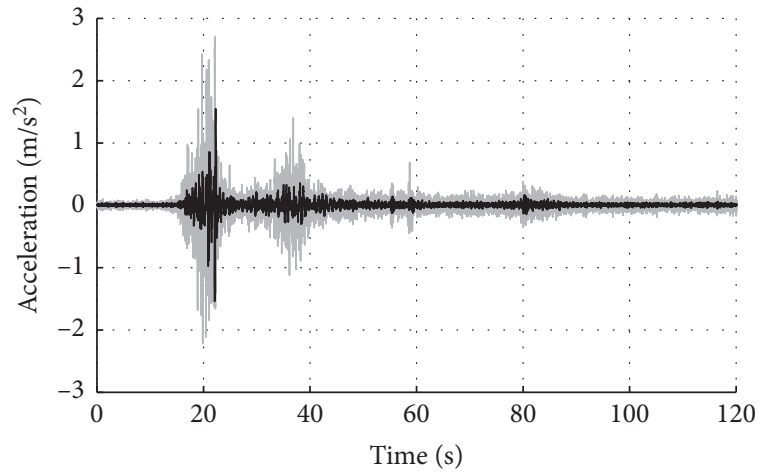

- Input acceleration time history

— Output acceleration time history

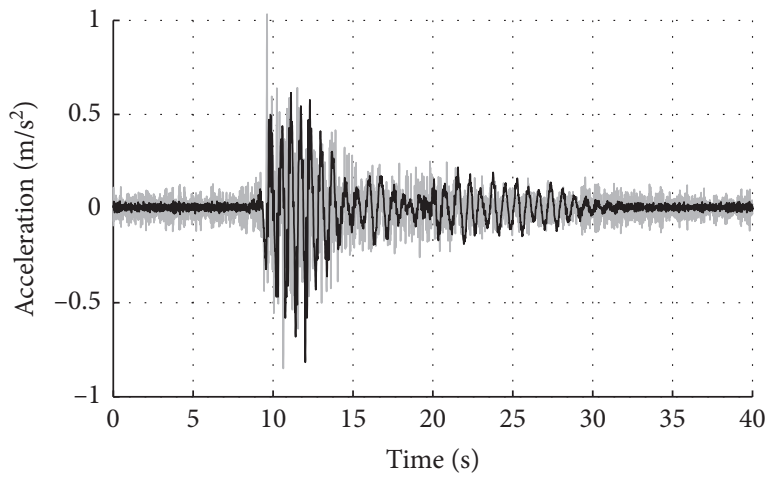

- Input acceleration time history

— Output acceleration time history

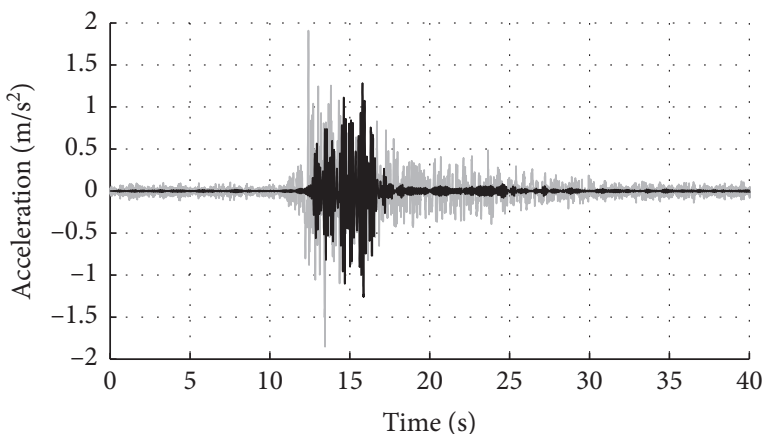

Input acceleration time history

_ Output acceleration time history

(e)

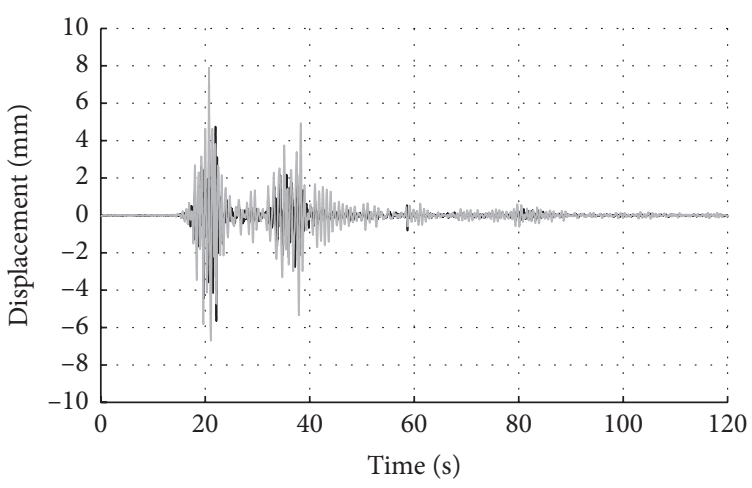

— Input displacement time history

_ Output displacement time history

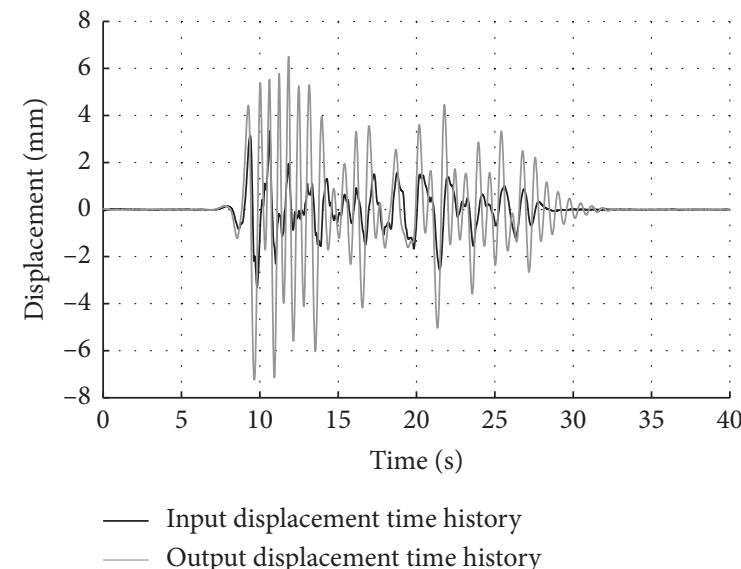

(f)

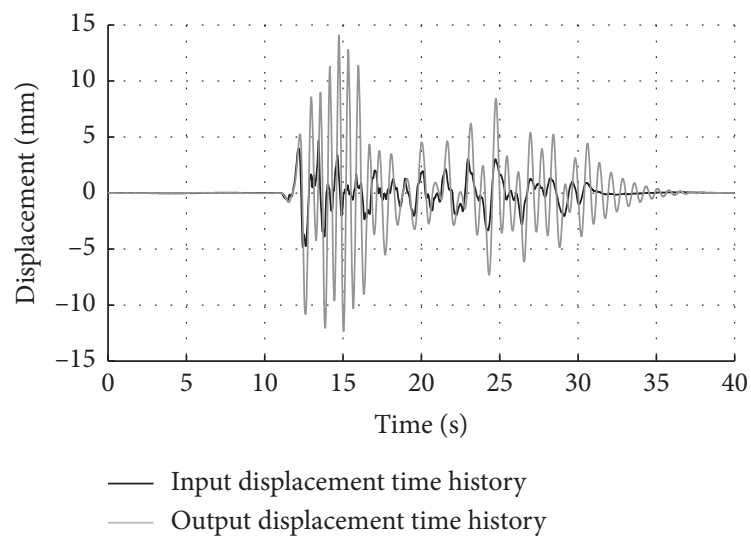

(g)

FIGURE 7: Acceleration and displacement time history: (a) WL0, (b) Taft0, (c) WL1, (d) WL2, (e) WL3, (f) Taft1, and (g) Taft2.

TABLE 2: Natural vibration period and damping ratio.

\begin{tabular}{lccc}
\hline Test no. & Natural vibration period $(\mathrm{s})$ & Damping ratio & Notes \\
\hline WN1 & 0.711 & 0.061 & Before the test, unfilled with asphalt \\
WN2 & 0.709 & 0.059 & After the test, unfilled with asphalt \\
WN3 & 0.689 & 0.118 & Before the test, filled with asphalt \\
WN4 & 0.698 & 0.123 & After the test, filled with asphalt \\
\hline
\end{tabular}


from $0.1 \mathrm{~g}$ to $0.3 \mathrm{~g}$. The detailed results are shown in Table 3. According to the results, the following conclusions could be found:

(1) The rebar isolation pier has a good isolation effect and effectively reduces the acceleration response of the superstructure; the acceleration decreases at least $40 \%$ in most tests. And the output displacement increased by nearly double, but all were within the range of $20 \mathrm{~mm}$, which could meet the requirements of normal use.

(2) Comparing the experimental data of WL1 and Taft1 with the data of WL0 and Taft0, we can see that the acceleration reduction rate of WL1 and Taft1 was less than WL0 and Taft0; it may be caused by the increase in stiffness of the isolation pier after adding asphalt ointment.

(3) It can be seen from Figure 7 that, during the experiment, when the input simulated seismic wave ends, the peak displacement of WL1 and Taft1 decreases rapidly, while the displacement of WL0 and Taft0 decreases slowly with time, and the displacement time-history curve presents the law of free vibration. This phenomenon verified that asphalt ointment played a damping role in the experiment and could well limit the displacement of the superstructure, especially after the ground vibration stopped.

4.3. Hysteresis Characteristics. Take the interlayer shear force of the isolated layer as the ordinate and the horizontal relative displacement as the abscissa. The hysteresis curve of the isolated layer can be drawn. The rebar isolation pier is a nonlinear composite structure consisting of vertical steel bars and asphalt ointment and the input seismic waves are not periodic, Therefore, the hysteresis curve of the rebar isolation pier is also nonlinear.

Taking the Wolong wave, for example (Figure 8), the following can be seen from the hysteresis curve of the rebar isolation pier:

After the addition of asphalt, the hysteresis curve was significantly fuller and the area of the curve was also larger, which indicated that the energy dissipation capacity of the isolation layer was improved after the addition of asphalt.

Comparing Figures 8(a) and 8(b), except for a few curves that deviate a lot from the origin, the hysteresis loop of the isolation pier filled with asphalt ointment is more concentrated; most of that is within the horizontal force of $-1.2 \sim 1.2 \mathrm{kN}$ and displacement of $-1.5 \mathrm{~mm} \sim 1.5 \mathrm{~mm}$. This indicates that the maximum horizontal force and displacement are greater than those without asphalt, but the asphalt ointment has a significant limitation on the horizontal force and displacement during the whole test.

\section{Analyses and Discussions with Energy Method}

5.1. Basic Principle of the Energy Method. When the structure is subjected to horizontal earthquake, the seismic energy is continuously transported to the structure system, one part of that is stored in the form of kinetic energy and recoverable elastic strain energy, and the other part of that is dissipated by the structure with its own damping and plastic deformation. Assuming that the structural system does not collapse during the earthquake motion, the total energy consumption of the structural system is balanced with the total energy input. Since the kinetic energy and elastic strain energy of the structure are only the mutual transformation of energy in earthquake motion and do not participate in energy consumption, the damage degree of the structure mainly depends on its energy-consuming capacity [16].

The energy method which starts from the energy dissipation capacity and considers energy-related factors can evaluate the safety and isolation effect of the structure from a new perspective, and the following basic assumptions need to be met in the analysis of isolation devices: first, the structure is completely symmetrical, regardless of the effect of torsion; second, the total input energy of the earthquake is all concentrated in the isolation layer, and the energy dissipation of the superstructure is ignored. In this way, not only is the structure model simplified, but also the energy dissipation capacity of the superstructure can be used as a safety reserve $[17,18]$.

Taking the rebar isolation pier as an example, it can be simplified into a single degree of freedom system (SDOF), and its differential equation of motion under the action of horizontal earthquake can be expressed as

$$
m \ddot{x}(t)+c \dot{x}(t)+f_{s}(x, \dot{x})=-m \ddot{x}_{g}(t),
$$

where $m$ is structure mass; $c$ is viscous damping coefficient; $f_{s}(x, \dot{x})$ is the hysteresis restoring force of the structure; $\ddot{x}, \dot{x}$, and $x$ are acceleration, velocity, and displacement relative to the ground; $\ddot{x}_{g}$ is absolute ground acceleration.

By taking the integral of the relative displacement $x$ of the particle at both sides of equation (2) within the timeholding range of ground motion $[0, t]$ and set $\mathrm{d} x=\dot{x} \mathrm{~d} t$, the relative energy response equation of the SDOF can be obtained:

$$
\int_{0}^{t} m \ddot{x} \dot{x} \mathrm{~d} t+\int_{0}^{t} c \dot{x} \dot{x} \mathrm{~d} t+\int_{0}^{t} f_{s} \dot{x} \mathrm{~d} t=-\int_{0}^{t} m \ddot{x}_{g} \dot{x} \mathrm{~d} t .
$$

The one on the right represents the total input energy of the structure underground motion $\left(E_{\text {in }}\right)$; the left three items represent the kinetic energy $\left(E_{v}\right)$, damping energy $\left(E_{c}\right)$, and 
TABLE 3: Details of max peak acceleration and displacement.

\begin{tabular}{|c|c|c|c|c|c|c|}
\hline \multirow[t]{2}{*}{ Test no. } & \multicolumn{2}{|c|}{$\begin{array}{c}\text { Max peak } \\
\text { acceleration }\left(\mathrm{m} / \mathrm{s}^{2}\right)\end{array}$} & \multirow[t]{2}{*}{ Acceleration reduction rate (\%) } & \multicolumn{2}{|c|}{$\begin{array}{c}\text { Max peak } \\
\text { displacement }(\mathrm{mm})\end{array}$} & \multirow[t]{2}{*}{ Displacement increase rate } \\
\hline & Input & Output & & Input & Output & \\
\hline WL0 & 0.996 & 0.244 & 75.6 & 1.507 & 3.561 & $236.3 \%$ \\
\hline Taft0 & 0.989 & 0.503 & 49.1 & 3.146 & 7.723 & $245.5 \%$ \\
\hline WL1 & 1.110 & 0.440 & 60.4 & 1.984 & 2.396 & $120.7 \%$ \\
\hline WL2 & 1.934 & 1.216 & 37.1 & 3.795 & 5.412 & $142.6 \%$ \\
\hline WL3 & 2.703 & 1.530 & 42.8 & 5.645 & 7.891 & $139.8 \%$ \\
\hline Taft1 & 1.033 & 0.816 & 21.0 & 3.342 & 7.232 & $216.4 \%$ \\
\hline Taft2 & 1.908 & 1.284 & 32.7 & 4.834 & 14.101 & $291.7 \%$ \\
\hline
\end{tabular}

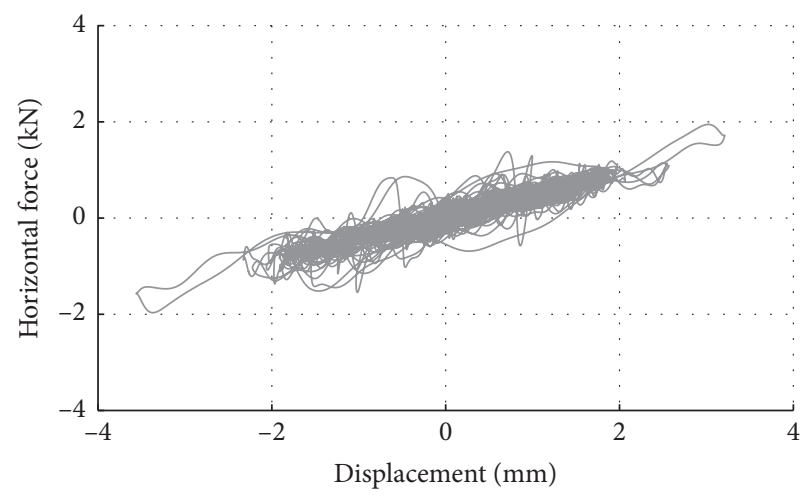

(a)

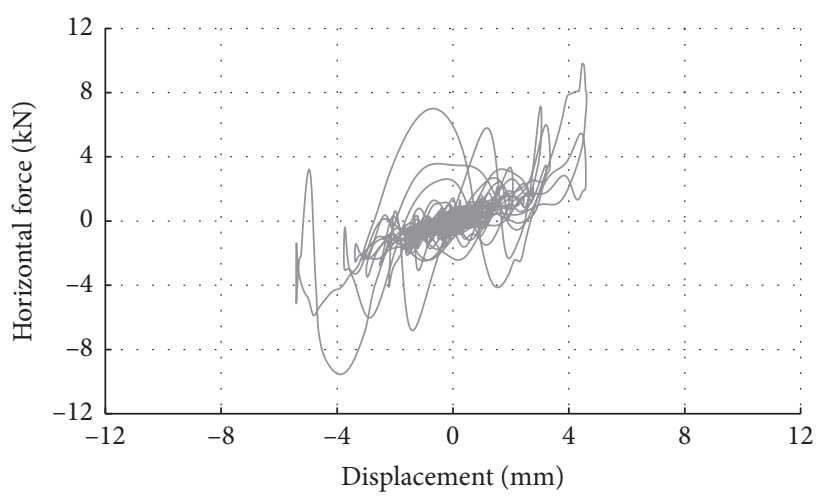

(c)

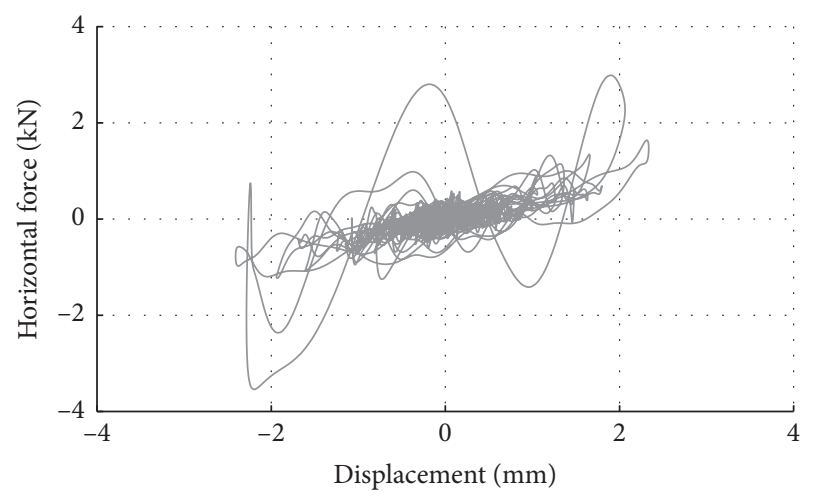

(b)

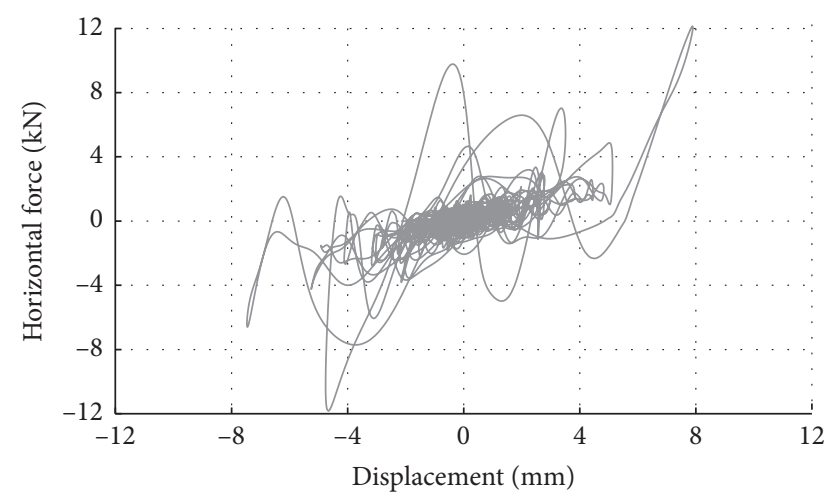

(d)

Figure 8: Hysteresis loops: (a) WL0, (b) WL1, (c) WL2, and (d) WL3.

deformation energy $E_{d}$ which is the sum of elastic strain energy $E_{k}$ and hysteretic energy $\left(E_{h}\right)$. Therefore, equation (3) can be shown as

$$
E_{v}+E_{c}+E_{k}+E_{h}=E_{\text {in }}
$$

The above equations are obtained in the relative coordinate system of the particle. In the absolute coordinate system, the corresponding absolute energy equation can be obtained by taking the integral of the absolute displacement of the particle at both sides of equation (2). The results show that the definition of system energy in the two coordinate systems is different, but it is mathematically equivalent, and when the natural vibration period of the structure is within the range of $0.3 \mathrm{~s}$ to $5 \mathrm{~s}$, there is little difference between the two different definitions.

5.2. Energy Analysis for the Rebar Isolation Pier. The experiment data of acceleration and displacement can be used to calculate the energy value.

As $E_{v}$ and $E_{k}$ are not directly dissipated energy, but only a process of energy transformation, not an accumulation process, when the earthquake motion is over, according to equation (4), $E_{v}$ and $E_{k}$ of the structure will return to zero, and the equation becomes

$$
E_{c}\left(t_{e}\right)+E_{h}\left(t_{e}\right)=E_{\text {in }}\left(t_{e}\right),
$$



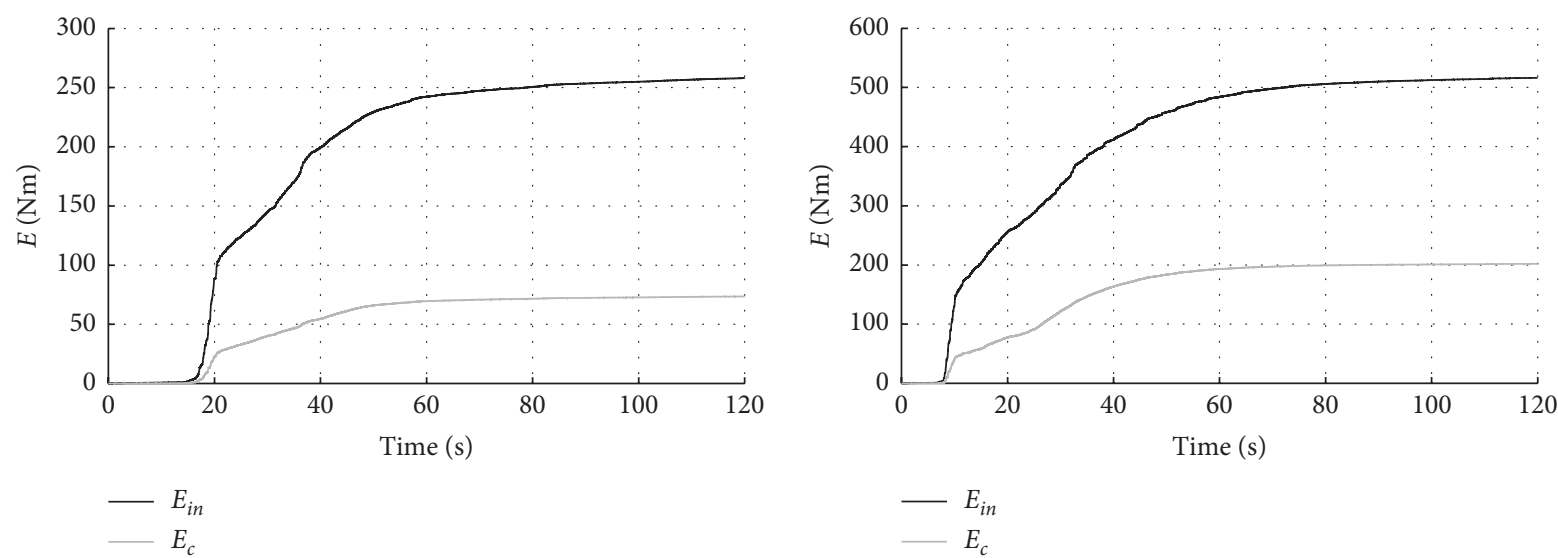

(a)

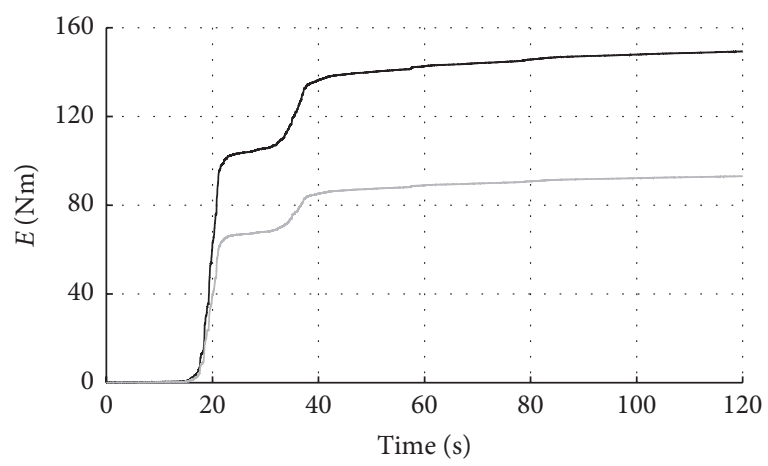

(b)

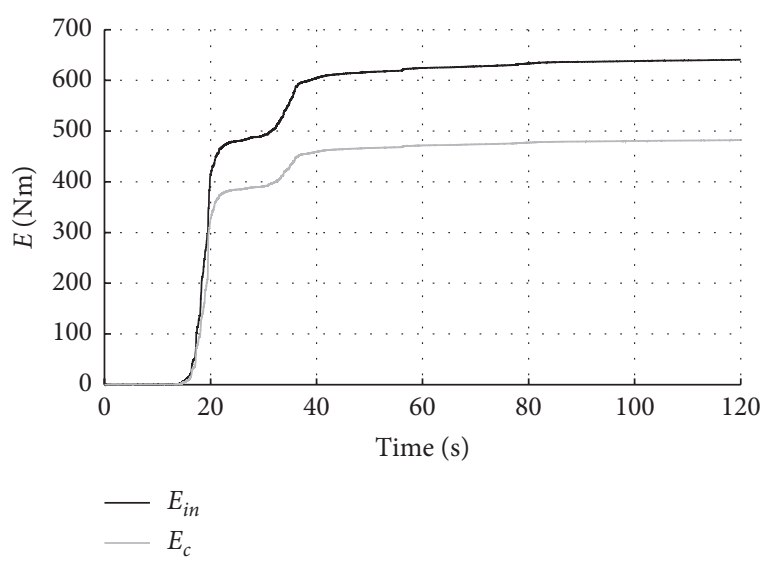

(c)
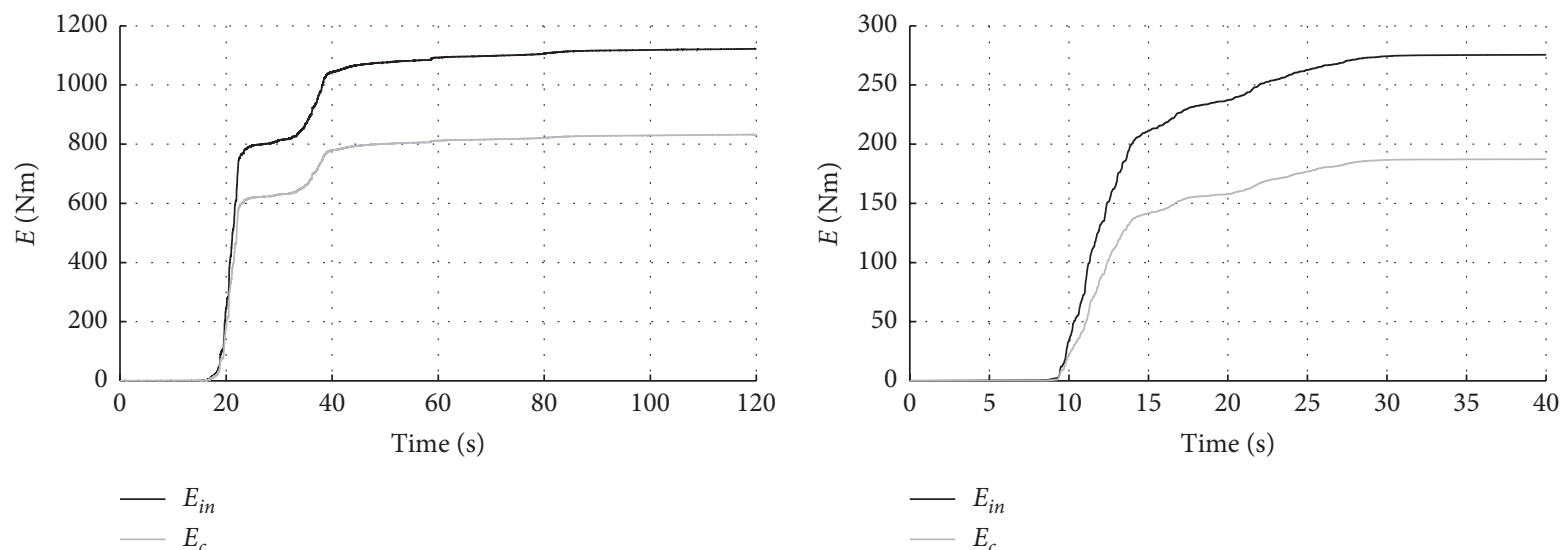

(e)

(f)

Figure 9: Continued. 


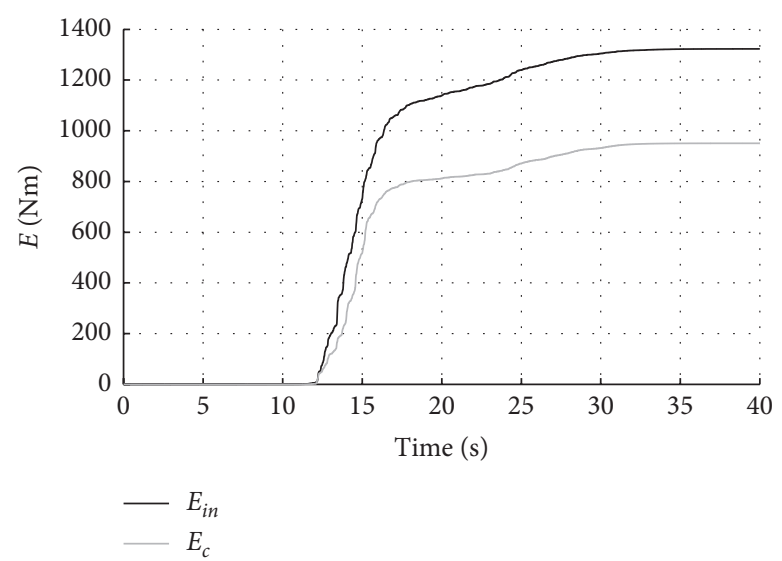

(g)

Figure 9: Curve of energy accumulation with time: (a) WL0, (b) Taft0, (c) WL1, (d) WL2, (e) WL3, (f) Taft1, and (g) Taft2.

TABLe 4: Details of energy analysis.

\begin{tabular}{lccr}
\hline Coed & Total input energy $E_{\text {in }}(\mathrm{Nm})$ & Damping energy $E_{c}(\mathrm{Nm})$ & Ratio of damping energy $E_{c} / E_{\text {in }}(\%)$ \\
\hline WL0 & 260.049 & 74.072 & 28.5 \\
Taft0 & 535.216 & 206.808 & 38.6 \\
WL1 & 150.030 & 93.53 & 62.3 \\
WL2 & 644.848 & 485.03 & 75.2 \\
WL3 & 1123.641 & 833.42 & 74.2 \\
Taft1 & 275.91 & 187.52 & 67.9 \\
Taft2 & 1324.14 & 951.19 & 71.8 \\
\hline
\end{tabular}

where $t_{e}$ is the duration of earthquake motion.

Since acceleration and displacement are discrete data collected at a fixed time during the tests, it cannot be calculated directly by using the integral formula. However, the time interval of data collected is very short, so $E_{\text {in }}$ and $E_{c}$ can be calculated by using the trapezoidal formula as follows [7]:

$$
\begin{aligned}
E_{\text {in }}(t) & =E_{\text {in }}(t-\Delta t)+0.5 m\left\{\left[\ddot{x}_{g}(t) \dot{x}(t)\right]^{2}-\left[\ddot{x}_{g}(t-\Delta t) \dot{x}(t-\Delta t)\right]^{2}\right\}, \\
E_{c}(t) & =E_{c}(t-\Delta t)+0.5 c\left[\dot{x}(t)^{2} t-n \dot{x} q(t-\Delta t)^{2}\right] .
\end{aligned}
$$

In calculating $E_{h}$, it is necessary to select appropriate hysteretic models, and different hysteretic models have a great influence on the calculation results [19]. Due to the fact that the rebar isolation pier has the characteristics of material nonlinearity, the hysteretic model is relatively complex, as shown in Figure 8, and it is difficult to select an appropriate hysteretic model. Therefore, in order to avoid increasing calculation error, $E_{h}$ was not directly calculated in this paper.

The curve of energy accumulation with time of WL0, WL1, WL2, and WL3 is shown in Figure 9, and the energy analysis results of all tests are shown in Table 4. As can be seen from them, one has the following: 
(1) By comparing the total input energy before and after adding asphalt ointment, it can be found that asphalt ointment can significantly reduce the input energy of earthquake. Under the same peak acceleration condition, $E_{\text {in }}$ of WL wave and Taft wave decreases by $42.3 \%$ and $48.4 \%$.

(2) Since asphalt ointment can significantly increase the damping of the structure, the proportion of damping energy is increased greatly. The rebar isolation pier consumes seismic energy mainly through damping which consumes $60 \%-75 \%$ of seismic energy in most experiments, but less than $40 \%$ in the absence of asphalt ointment.

(3) With the increase of the peak acceleration of the input seismic wave, the total input energy and damping energy both increase greatly, which presents nonlinear characteristics. But the damping energy ratio increases slightly and remains unchanged basically.

\section{Conclusions}

In this paper, a new rebar isolation pier for the base isolation is proposed, and its isolation effect is analyzed and verified by using acceleration method and energy method. Through the experimental results and analysis, the following conclusions can be made:

(1) The rebar isolation pier is a new type of seismic isolation system with advantages of simple structure, easy manufacture, low cost, and good isolation effect. It is suitable for low-rise buildings in rural and underdeveloped areas.

(2) The rebar isolation pier has good isolation performance, which can effectively reduce the input acceleration. The acceleration reduction rate is greater than 0.4 in most tests, and the increase in displacement is also acceptable.

(3) After the experiment, the vertical steel bars return to their original position, and the change of natural vibration characteristics before and after the tests is very small, which indicates that the simulated ground vibration in the experiment has little damage to the rebar isolation pier, and the isolation pier still has safety reserves. And the reasonable design of the number, diameter, and free height of the vertical steel bars can ensure that the rebar isolation pier meets the isolation requirements of various conditions.

(4) After adding asphalt ointment, the natural vibration period of the isolation pier decreases slightly, and the rate of acceleration reduction decreases with it, but the damping ratio increases significantly, and the rate of displacement increase decreases accordingly. In the whole experiment process, the limitation of asphalt ointment on displacement is very obvious, especially after the end of the input seismic wave.

(5) In the isolation system of the rebar isolation pier, the total input energy and damping energy of the structure increase with the peak acceleration of seismic wave, which presents nonlinear characteristics. The rebar isolation pier consumes seismic energy mainly through damping which consumes $60 \%-75 \%$ of seismic energy in most experiments.

(6) In the rebar isolation pier, asphalt ointment can significantly reduce and dissipate the total input energy of the structure, improve the isolation performance of the structure, and also play a role in rust prevention. Therefore, it is necessary to add asphalt ointment to the rebar isolation pier.

\section{Data Availability}

All analyzed data (except for the original experimental data) used during the study are available from the first author upon request.

\section{Conflicts of Interest}

The authors declare that they have no conflicts of interest.

\section{Acknowledgments}

Thanks are due to the National Civil Engineering Experimental Teaching Demonstration Center of Shandong Jianzhu University for its help in the experimental equipment, materials, and model making. This research was funded by Key Projects in the National Science \& Technology Pillar Program during the Twelfth Five-Year Plan Period (2015BAL03B01).

\section{References}

[1] H. Li, Z. Xu, S. Ma, and J. Zhao, "Research progress on faulting and dynamic processes of the 2008 Wenchuan and 2017 Jiuzhaigou earthquakes," Chinese Journal of Geophysics, vol. 61 , no. 5 , pp. 1653-1665, 2018.

[2] J. Takeda, Building Isolation and Vibration Control, pp. 1-22, China Architecture and Building Press, Beijing, China, 1997.

[3] Y. N. Sonawane, "Study between laminated rubber bearings and friction pendulum bearing of base isolation system: a review," International Journal for Research in Applied Science and Engineering Technology, vol. 6, no. 3, pp. 2824-2828, 2018.

[4] I. G. Buckle and R. L. Mayes, "Seismic isolation: history, application, and performance-a world view," Earthquake Spectra, vol. 6, no. 2, pp. 161-201, 1990.

[5] A. H. Deringöl and E. M. Güneyisi, "Effect of friction pendulum bearing properties on behaviour of buildings subjected to seismic loads," Soil Dynamics and Earthquake Engineering, vol. 125, Article ID 105746, 2019.

[6] A. Mokha, M. C. Constantinou, A. M. Reinhorn, and V. A. Zayas, "Experimental study of friction-pendulum isolation system," Journal of Structural Engineering, vol. 117, no. 4, pp. 1201-1217, 1991.

[7] C.-M. Uang and V. V. Bertero, "Evaluation of seismic energy in structures," Earthquake Engineering \& Structural Dynamics, vol. 19, no. 1, pp. 77-90, 1990.

[8] T. F. Zahrah and W. J. Hall, "Earthquake energy absorption in SDOF structures," Journal of Structural Engineering, vol. 110, no. 8, pp. 1757-1772, 1984. 
[9] Y. Zhou, T. Xu, and F. Zhou, "Research and development of structural seismic design based on energy method," Earthquake Engineering and Engineering Dynamics, vol. 3, pp. 116-122, 2000.

[10] J. Su and D. Zeng, "Research and application of seismic isolation of building in China," Earthquake Engineering and Engineering Dynamics, vol. 1, pp. 94-101, 2001.

[11] Ministry of Housing and Urban-Rural Development of China, Code for Seismic Design of Buildings (GB50011-2011), China Architecture \& Building Press, pp. 31-40, Beijing, China, 2011, in Chinese.

[12] Y. Huang, "Review of research on seismic safety of rural residences in Hunan province, China," Journal of Natural Disasters, vol. 2, pp. 37-48, 2019.

[13] G. Jia and Z. Shi, "A new seismic isolation system and its feasibility study," Earthquake Engineering and Engineering Vibration, vol. 9, no. 1, pp. 75-82, 2010.

[14] S. Shang and Y. Qiao, "Research on elastoplastic design of the steel-asphalt isolation layer," Earthquake Engineering and Engineering Dynamics, vol. 1, pp. 35-41, 2019.

[15] F. Qiu, J. Qian, and Z. Chen, Seismic Test Methodology for Structures, Science Press, pp. 47-50, Beijing, China, 2000.

[16] A. Filiatrault, P. Léger, and R. Tinawi, "On the computation of seismic energy in inelastic structures," Engineering Structures, vol. 16, no. 6, pp. 425-436, 1994.

[17] L. D. Decanini and F. Mollaioli, "An energy-based methodology for the assessment of seismic demand," Soil Dynamics and Earthquake Engineering, vol. 21, no. 2, pp. 113-137, 2001.

[18] M. Xiao, B. Liu, and S. Bai, "Analysis of the total energy and its influencing factors for seismic structures," Journal of Chongqing Jianzhu University, vol. 18, pp. 20-33, 1996.

[19] J. M. Tembulkar and J. M. Nau, "Inelastic modeling and seismic energy dissipation," Journal of Structural Engineering, vol. 115, pp. 1279-1282, 1989. 